УДК 349.222

Т. Ф. Вышеславова, С. А. Лукинова

\title{
ФОРМАЛЬНАЯ ОПРЕДЕЛЕННОСТЬ В ИНСТИТУТЕ ТРУДОВОГО ДОГОВОРА
}

Статья посвящена правовому анализу уровня формальной определенности норм института трудового договора в трудовом праве. В ней определены основные признаки оценочных понятий данного института, их роль в обеспечении полноты конкретизации трудовых правоотношений, подлежащих правовому регулированию. Рассматривается значение объективно-субъективного анализа применения оценочных понятий института трудового договора, через анализ конкретных обстоятельств исходя из специфики социально-трудовых правоотношений, частичной конкретизации норм института трудового договора в Трудовом кодексе РФ, локального регулирования трудовых отношений и судебной практики в унификации формальной определенности норм института трудового договора. Авторы приходят к выводу, что фрормальная определенность норм института трудового договора опосредуется субъективно-индивидуальным характером трудовых правоотношений. Отличительной чертой оценочных норм исследуемого института является целенаправленная, запрограммированная необходимость в формальной определенности многообразных правовых явлений, неподлежащих конкретному перечню в Трудовом кодексе РФ. Лаконичное изложение текста правовой нормы предполагает неизбежность присутствия отдельных оценочных положений в регулировании трудового договора. Правильное (то есть соответствующее идее законодателя) понимание оценочного понятия трудового права при его реализации в правоотношениях имеет огромное значение, так как только оно обеспечивает соответствие нормативного предписания целям, преследовавшимся законодателем при его принятии.

Ключевые слова: формальная определенность; оценочные нормы; институт трудового договора; законодательное регулирование; деловые качества; исключительные случаи; судебная практика.

\section{T. F. Vysheslavova, S. A. Lukinova}

\section{FORMAL DEFINITION IN THE INSTITUTE OF LABOUR CONTRACT}

The article is devoted to the legal analysis of formal certainty level of the norms of the labor contract institution in the labor law. It defines the main features of the evaluative concepts of this institution, their role in ensuring the completeness of the specification of labor relations that are subject to legal regulation. The importance of an objective-subjective analysis of the application of evaluative concepts of the labor contract institute is analyzed through the analysis of specific circumstances based on peculiarities of social and labor legal relationships, partial specification of the norms of the labor contract institution in the Labor Code of the Russian Federation, local regulation of labor relations and judicial practice in unifying the formal certainty of the norms of the labour contract institute. The authors come to the conclusion that the formal certainty of the norms of the labour contract institution is mediated by the subjective-individual

Никто не будет оспаривать положение о том, что формальная определенность явля- nature of the employment relationship. A distinctive feature of the evaluative standards of the institution under study is a purposeful, programmed need for formal certainty of diverse legal phenomena that are not included in a specific list in the Labor Code of the Russian Federation. A laconic statement of the text of the legal norm presupposes the inevitability of the presence of certain evaluative provisions in the regulation of the employment contract. The correct (that is, corresponding to the idea of the legislator) understanding of the evaluative concept of labor law when it is implemented in legal relationships is of great importance, since only it ensures compliance of the normative order with the goals pursued by the legislator in its adoption.

Key words: formal certainty; estimated norms; institute of labor contract; legislative regulation; business qualities; exceptional cases; arbitrage practice.

ется важнейшим свойством трудового права, репрезентирующая систему социально-трудо- 
вых норм как универсального регулятора общественных правоотношений в сфере наемного труда. Таким образом, многие институты трудового права характеризуются наличием оценочных норм, не исключением является и институт трудового договора. Данный институт развивался по пути закрепления системы понятий и категорий, межпредметных понятийных связей. Как отмечает К. С. Романкулов: «Как и любые научные понятия, понятия, используемые в трудовом праве, обозначаются терминами и составляют наиболее информативную, наиболее важную в функциональном отношении часть этой отрасли права» [11, с. 158].

В современных трудовых отношениях довольно сложно создать абсолютно-определенные нормы, которые бы описывали все возможные практические ситуации во всем многообразии правовых отношений, что и обусловливает наличие оценочных норм института трудового договора.

Оценочные нормы, определение которых формулировались учеными в различных отраслях права [4; 5; 6], сводятся к тому, что под ними необходимо понимать особый прием юридической техники, закрепляющий наиболее общие юридические признаки, свойства, явления, не конкретизируемые законодателем, имеющие только относительно-определенное содержание, что позволяет осуществлять разноуровневую, в пределах зафиксированной в ней общности, индивидуальную регламентацию общественных отношений, с соблюдением функционального предназначения нормативного предписания. Отсюда, данная конкретизация обязана обеспечить юридическую определенность, ясность, логичность, недвусмысленность правовой нормы, а также не нарушать баланса прав и интересов участников трудового правоотношения.

Однако трудовое право, опираясь на свою специфику, где договорный метод регулирования конкурирует с императивным методом, требует выведения отдельных аспектов трудового договора за рамки полного законодательного регулирования. Отдельные положения данного института трудового права только фрормируют общую правовую инфрормацию для правоприменителя.

Оценочные нормы в институте трудового договора встречаются в ст. 58 - заключение срочного трудового договора при отсутствии достаточных к тому оснований; ст. 64 - необоснованный отказ в заключении трудового договора; ст. 67 - уполномоченный представитель; ст. 71 - предложенная работа не является под- ходящей; ст. 80 - невозможность продолжения работы; ст. 81 п. 3 - недостаточная квалификация; ст. 81 п. 7.1 - утрата доверия к работнику; ст. 81 п. 8 - аморальный проступок; ст. 81 п. 9 необоснованное решение; ст. 178 - исключительные случаи; ст. 180 - массовое увольнение и прочее.

Формальная определенность норм института трудового договора опосредуется объективно-субъективным анализом рассматриваемой конкретной ситуации исходя из специфики социально - трудовых правоотношений. Поэтому можно полагать, что использование оценочных понятий в сфере наемного труда неизбежно и даже в какой-то степени необходимо при более полном охвате отношений, подлежащих правовому регулированию при лаконичном изложении текста правовой нормы. Этот вывод работает и в других отраслях права, например в налоговом праве. Так, по мнению А. А. Пелипенко, «субъективная оценка должна отображать в налоговом праве явления морального, этического и нравственного характера, придавать системе налогообложения гибкость, обеспечивать полноту и динамичность налогового законодательства» [10, с. 24].

В вопросе определенности норм института трудового договора решающую роль играют указания Трудового кодекса РФ, на сколько законодатель разрешает свободу принятия решений правоприменителя в отдельных конкретных случаях. В большинстве случаев объем усмотрения правоприменителя ограничивается нормами, содержащимися в актах трудового законодательства и иных нормативно-правовых актах, содержащих нормы трудового права. Примером может служить ст. 56 ТК РФ, где перечисляются обязательные условия трудового договора, которые могут быть дополнены условиями, «в случаях, предусмотренных трудовым законодательством и иными нормативными правовыми актами, содержащими нормы трудового права».

Особенностью оценочных понятий института трудового договора является возможность для работодателя злоупотребление своими полномочиями в трактовке и оценке отдельных норм в своих интересах. Он может отказать работнику в расторжении трудового договора по собственному желанию в срок, указанный в заявлении работника, на основании своего понимания невозможности продолжения работы (п. 3 ст. 80ТК РФ).

В вопросе определенности норм института трудового договора обращает на себя внимание наличие в ТК РФ частичной конкретизации, 
служащей ориентиром для правоприменителя. Так, ст. 56 ТК РФ при формулировании условия трудового договора о характере работы по трудовому договору в необходимых случаях, указывает на подвижной, разъездной, в пути и другие характеристики работы. Однако, такая конкретизация ведет на дополнительные выплаты работнику, которая не выгодна работодателю, отсюда конкретизация зачастую просто игнорируется работодателем.

Или работодатель сам принимает решение об уважительности отсутствия работника на рабочем месте и фиксации для него прогула. Критериев уважительности в данном случае нет при частичной конкретизации понятия «прогул». В данном случае необходима оценка всей совокупности обстоятельств и мотивов при принятии решения об уважительности отсутствия работника на рабочем месте в случаях указанных в законе.

Законодателем осуществляется фрормализация определенности института трудового договора и через применение синонимов юридической терминологии. Нормы расторжения трудового договора (ст. 77-84 ТК РФ) применяют несколько терминов обозначающих прекращение трудового правоотношения - увольнение, расторжение, прекращение трудового договора, однако создающие для работника в отдельных случаях различные правовые последствия. Так инициатором прекращения трудового договора может выступать и не участник трудового правоотношения, например МСЭК признающая работника инвалидом с невозможностью продолжения выполнения трудовой фрункции.

В конкретизации понятийного аппарата института трудового договора большое значение играет судебная практика. Так Постановление Пленума Верховного Суда РФ от 17.03.2004 г. №2 «О применении судами Российской Федерации Трудового кодекса Российской Федерации» наполнило содержанием понятие «деловые качества работника». А понятие «аморальный проступок» остается оценочным, несмотря на обращение Верховного Суда РФ к данной категории. Так Постановление №2 только устанавливает перечень лиц, занимающихся воспитательной деятельностью, а не дает самого понятия аморального проступка. Поэтому работодателю самому приходится решать входит ли проступок работника в квалификацию аморального. Такой проступок должен быть виновным и нарушать нормы морали и нравственности. «Аморальный» понятие, которое изменяется во-времени. Его современное содержание подвергается интерпретации согласно социально-экономическому развитию страны и других характеристик. Отсюда первостепенное значение приобретает комплексный подход к установлению моральных установок правомерного поведения участников трудового правоотношения. Но как различить аморальный проступок и неэтичный поступок работника. Конечно, невозможно перечислить в нормативном акте все проступки категории аморальных, они могут быть достаточно разнообразны. Отсюда правоприменитель как правосозидатель наполняет содержанием незавершенность конструкции правовой оценочной нормы. Таким образом, отдельные законодательные характеристики восполняются постановлениями Верховного Суда РФ в силу объективной необходимости и широко применяются правоприменителями.

Особую роль в сфере формальной определенности института трудового договора законодатель возлагает и на включение в него открытых перечней, расширяющих или дополняющих содержание сформулированной в Трудовом кодексе статьи на локальном уровне. Примерами могут служить ст. 73, где при отстранении работника от работы в связи с медицинским заключением, заработная плата может начисляться, если это будет предусмотрено коллективным договором или ст. 57 при включении в трудовой договор дополнительных условий.

Формализация охватывает и такие случаи, когда законодателем предусмотрено логическое построение субъективно-индивидуальной интерпретации оценочной нормы. Так дополнительные условия трудового договора не должны ухудшать положения работника по сравнению со всей иерархией норм трудового права. Такое широкое понятие дополнительных условий охватывает все аспекты социально-трудовой деятельности в сфере наемного труда и отражает особую приспособляемость эффективной реализации трудового правоотношения.

Остановимся на отдельных оценочных нормах института трудового договора. При заключении трудового договора такое понятие как «незаконный отказ» относится к неурегулированной в праве дефиниции. Каждая сторона трудового отношения будет трактовать ее по-своему. В литературе дается лишь перечень обстоятельств, при которых отказ считается необоснованным.

Под необоснованным отказом надлежит понимать: 
- отказ, противоречащий конституционной норме о дискриминации или императивным указаниям самого ТК РФ. Например, отказ в заключение трудового договора пенсионеру, инвалиду, имеющему индивидуальную программу реабилитации, беременной женщине или гражданину, не имеющему регистрации в данном населенном пункте;

- отказ, противоречащий существующим на самом деле обстоятельствам. Например, отказ из-за окончания не того вуза или сокрытия наличия вакансий. Неправомерным будет считаться и отказ в трудоустройстве без указания мотивов. Таким образом, необоснованный отказ в заключение трудового договора - это отказ, нарушающий нормы гарантий трудового законодательства о заключении трудового договора и не соответствующий фактическим обстоятельствам.

Деловые качества работника - оценочная категория. Дать исчерпывающее определение деловых качеств работника невозможно. Категория «деловые качества» трактуются по-разному, что иногда приводит к трудовым спорам, в связи с использованием произвольного толкования этого понятия.

Отказ в трудоустройстве часто вызван дискриминационными причинами. В трудовом праве нет точного и всеобщего понятия дискриминации, ее наличие необходимо определять в каждом конкретном случае. Дискриминационные основания предусмотрены в ст. 64 ТК РФ, и это лишь примерный перечень. В связи с этим, при возникновении вопроса о том, имела ли место дискриминация при отказе в заключение трудового договора, он решается судом при рассмотрении конкретного дела.

В п. 11 Постановления Пленума Верховного Суда РФ от 17.03.2004 №2 указывается на необходимость обратить внимание судов на то, что отказ работодателя в заключение трудового договора с лицом, являющимся гражданином РФ, в случае отсутствия регистрации, противоречит конституционной норме о свободе передвижения и является незаконным. При этом в Постановлении №2 нерешенным остается вопрос - о возможности взыскания заработной платы за время вынужденного прогула в связи с необоснованным отказом в принятии на работу.

Практика в данном случае складывается по пути понуждения работодателя заключить с соответствующим лицом трудовой договор и взыскания заработной платы за время вынужденного прогула. Так, определением Верховного Суда РФ от 23.03.2012 №8-ВПР12-4 иск в части требований о восстановлении на работе и взыскании компенсации морального вреда был удовлетворен, что в свою очередь означает понуждение работодателя заключить трудовой договор и взыскание заработной платы за время вынужденного прогула [7].

В трудовом праве не возникает какой-нибудь вид юридической ответственности при злоупотреблении работодателем своих прав. Сама формулировка такого правонарушения ни разу не встречается в ТК РФ. А это говорит о том, что такое злоупотребление не является причиной возникновения юридической ответственности и применения к нарушителю санкций трудового права [2].

Таким образом, судебная практика расширяет формальную определенность отдельных категорий института трудового договора, обеспечивая относительную ясность и конкретность правовой нормы. Однако в юридической литературе можно встретить мнение об отрицании «судебного права». Так И. А. Глотова рассматривает вопрос формализации определенности судебной практикой в таком ракурсе: «нам представляется, что у Верховного Суда РФ нет права принимать «оригинальные и не дублируемые законом положения», «восполнять имеющиеся в законе пробелы», «творить новые нормы «судебного» права». Это, на наш взгляд, противоречит ст. ст. 10, 11 Конституции РФ, устанавливающим систему разделения властей в Российской Федерации, и ст. 126 Конституции РФ, устанавливающей компетенцию Верховного Суда РФ» [1, с. 6].

По нашему мнению, факт «судебного права» уже широко применяется правоприменителем, и отрицать его эффрективность в институте рудового договора было бы ошибочным.

Понятие «утрата доверия» включается в ст. 81 п. 7 и 7.1 ТК РФ распространяющееся на работников обслуживающих денежные и товарные ценности и лиц, относящихся к государственным служащим, обязанным представлять сведения об имущественном положении и пользовании иностранными фринансовыми инструментами. Понятие является оценочным, не имеющим легального определения ни в ТК РФ, ни в Постановлении Пленума Верховного Суда РФ №2. Определение Судебной коллегии по гражданским делам Верховного Суда № 14В-99пр-8, говорит о том, что такое основание как «утрата доверия» может быть применено самостоятельно, и наличия вступившего в силу приговора суда не требуется [9]. По мнению Е. Степановой «достаточно конкретного фракта совершения лицом гражданского персо- 
нала виновных действий, дающих основание для утраты к нему доверия со стороны командования воинской части» [12, с. 74].

Таким образом, основание «утрата доверия» при прекращении трудового договора будет применимо при отказе в определенных действий, установленных ТК РФ, сомнениях работодателя в честности, добропорядочности, правдивости работников, а также в «искренности мотивов поступков, способности эфффективно исполнять свои обязанности» [3, с. 80]. Все это дает большой простор усмотрению работодателя применения данного основания при расторжении трудового договора, тем более, что обширная судебная практика в трудовых отношениях по данной категории дел отсутствует.

Последствия применения основания «утрата доверия» для разных категорий работников различны. Так для работников, обслуживающих товарные и денежные ценности на основании трудового договора последствия не предусмотрены. Для государственных и муниципальных служащих установлены такие последствия ст. 64.1 ТК РФ. В данном случае в ТК РФ предпринята попытка соединения трудового и административного правоотношения в рамках единообразного регулирования.

Требует внимания и такая оценочная категория как «в исключительных случаях», закрепленная ст. 178 при сохранении работнику среднего месячного заработка за третий месяц, если увольнение произведено по основанию сокращения или ликвидации организации. Судебная практика шла по пути автоматического присуждения выплаты выходного пособия при данном основании увольнения [9]. Однако данное положение в настоящее время меняется. Так обзоры судебной практики Верховного суда за 2017 год уже не говорят о безоговорочном праве работников на сохранение заработной платы на период трудоустройства за третий месяц даже при наличии регистрации в Государственной службе занятости в качестве безработных в течение установленного времени.

Оценочное понятие массового увольнения, закрепленного в ст. 180 ТК РФ, которое находит формализованное определение через нормы Положения об организации работы по содействию занятости в условиях массового высвобождения, утвержденного постановлением Правительства РФ от 05.02.1993 г. №99. В данном документе определены критерии признания увольнения массовым. Юридически значимыми обстоятельствами для признания высвобождения массовым являются: основания увольнения работников, а также численность работников, подлежащих увольнению.

Таким образом, оценочными понятиями в институте трудового договора можно считать закрепленные в ТК РФ понятия с открытой юридической структурой, предполагающей их конкретизацию участниками трудовых правоотношений или судебной практикой. Отличительной чертой оценочных норм исследуемого института является целенаправленная, запрограммированная необходимость в формальной определенности многообразных правовых явлений, неподлежащих конкретному перечню в Трудовом кодексе РФ. В трудовом праве особую роль играют правовые гарантии правильного применения оценочных понятий при реализации норм института трудового договора. Возрастает значение правосознания участников трудового правоотношения, применяющих данные понятия и фрормализующих на практике эффективность их действия. Оценочные нормы института трудового договора являются неотъемлемой частью правовой системы отрасли трудового права. Многие оценочные понятия института трудового договора могут применяться с учетом конкретной ситуации, согласуясь с принципами трудового права и уровнем правовой культуры правоприменителя.

Также в конкретизации фрормальной определенности правовых норм играет судебная практика, которая вырабатывает отдельные правоположения, основанные на многократном применении. Практика не исключает возможных ошибок в толковании оценочных понятий работодателем в реализации норм института трудового договора. Даже суды принимают кардинально противоположные решения при рассмотрении схожих обстоятельств, особенно в части правомерности расторжения трудового договора. Отсюда, правоприменитель наполняет содержание оценочной нормы определенным смыслом в конкретной ситуации и обстоятельствах. Оценочные понятия института трудового договора находятся в рамках своего содержания в процессе правоприменения. Они не представляют собой неограниченное усмотрение работодателя, а значит, не являются полностью неопределенными, что на практике, с определенным уровнем, обеспечивают единообразный характер применения норм института трудового договора.

Формальная определенность института трудового договора выступает гарантом устойчивости реализации прав и законных интересов участников трудового правоотношения, обе- 
спечивая унисрикацию и устойчивость правопорядка в трудовом праве. Формализация препятствует неограниченному усмотрению работодателя в реализации работником своих трудовых прав.

\section{Литература}

1. Глотова И. А. Понятие и способы конкретизации норм в трудовом праве // Трудовое право в России и за рубежом. 2013. №4. C. 6.

2. Киселев А. О некоторых проблемах мотивирования отказов в приеме на работу // Доступ из СПС «Консультант-Плюс».

3. Корякин В. М., Филиппова М. Ю. Утрата доверия как основание расторжения трудового договора: проблемы правового регулирования // Аграрное и земельное право. 2016. №6. С. 80.

4. Лукьяненко М. Ф. Оценочные понятия гражданского права: разумность, добросовестность, существенность. М.: Статут, 2010. 423 с.

5. Миронов А. В. Оценочные понятия в избирательном законодательстве Российской Федерации. Иркутск: Изд-во института законодательства и правовой политики, 2005. 224 с.

6. Смирнов Д. А. Принципы российского налогового права: понятие, формирование, реализация / под ред Н. И. Химичевой. М.: Юрлитинфоорм, 2011. 248 с.

7. Определение Верховного Суда РФ от 23.03.2012. № 8-ВПР12-4 [Электронный ресурс] // Доступ из СПС «Консультант-Плюс».

8. Обзор судебной практики Верховного Суда Российской Федерации за первый квартал 1999 г. (утвержден Постановлением Пленума Верховного Суда Российской Федерации от 9 июня 1999 г.) // Доступ из СПС «Консультант-Плюс».

9. Определение Верховного Суда РФ от 27.03.2017 г. № 69-КГ 16-18 [Электронный ресурс] // Доступ из СПС «Консультант-Плюс».

10. Пилипенко А. А. Научный дискурс по вопросу применения оценочных понятий в налоговой сфрере // Финансовое право. 2017. № 2. С.24.

11. Раманкулов К. С. Вопросы развития понятийного аппарата трудового права государств - членов ЕАЭС // Российский юридический журнал. 2017. № 3. С. 158.

12. Степанова Е. Увольнение по причине утраты доверия: при каких обстоятельствах оно возможно? // Трудовое право. 2014. №9. С. 74.

\section{References}

1. Glotova I. A. Ponjatie i sposoby konkretizacii norm v trudovom prave (The concept and the ways to specify the norms of labor rights) // Trudovoe pravo v Rossii i za rubezhom. 2013. No. 4. P. 5-8. (In Russian).

2. Kiselev A. O nekotoryh problemah motivirovanija otkazov $v$ prieme na rabotu (On some problems of motivation of employment refusals) // Konsul'tant Pljus (In Russian).

3. Korjakin V. M., Filippova M. Ju. Utrata doverija kak osnovanie rastorzhenija trudovogo dogovora: problemy pravovogo regulirovanija (Loss of confidence as a ground of terminating the employment contract: legal issues) // Agrarnoe i zemel'noe pravo. 2016. No. 6. P. 72-83. (In Russian).

4. Lukyanenko M. F. Ocenochnye ponjatija grazhdanskogo prava: razumnost', dobrosovestnost', sushhestvennost' (Evaluation of the concept of civil law: reasonableness, good faith, materiality). Moscow: Statut. 2010. 423 p. (In Russian).

5. Mironov A. V. Ocenochnye ponjatija v izbiratel'nom zakonodatel'stve Rossijskoj Federacii (Evaluative concepts in the electoral legislation of the Russian Federation). Irkutsk: Institut zakonodatel'stva i pravovoj politiki, 2005. 224 p. (In Russian).

6. Smirnov D. A. Principy rossijskogo nalogovogo prava: ponjatie, formirovanie, realizacija (Principles of Russian tax law: concept, formation, implementation) / ed. by N. I. Himichevoj. Moscow: Jurlitinform, 2011. 248 p. (In Russian).

7. Opredelenie Verhovnogo Suda RF ot 23.03.2012. № 8-VPR12-4 (The determination of the Supreme Court of 23.03.2012. № 8-VPR12-4) // Konsul'tant-Pljus. (In Russian).

8. Obzor sudebnoj praktiki Verhovnogo Suda Rossijskoj Federacii za pervyj kvartal 1999 g. (utverzhden Postanovleniem Plenuma Verhovnogo Suda Rossijskoj Federacii ot 9 ijunja 1999g) (The overview of court practice of the Supreme Court of the Russian Federation for the first quarter of 1999 (approved by the Resolution of Plenum of the Supreme Court of the Russian Federation of 9 June 1999) // Konsul'tant-Pljus. (In Russian).

9. Opredelenie Verhovnogo Suda RF ot 27.03.2017g. № 69-KG 16-18 (The determination of the Supreme Court from 27.03.2017g. № 69-KG 16-18) // Konsul'tant-Pljus. (In Russian).

10. Pilipenko A. A. Nauchnyj diskurs po voprosu primenenija ocenochnyh ponjatij v nalogovoj sfere (Scientific discourse on the application of evaluation concepts in the tax area) // Finansovoe pravo. 2017. No.2. P. 23-26. (In Russian).

11. Ramankulov K. S. Voprosy razvitija ponjatijnogo apparata trudovogo prava gosudarstv - chlenov EAJeS (The issues of developing a conceptual framework of labor law of EAEU member-states) // Rossijskij juridicheskij zhurnal. 2017. No. 3. P. 153-163. (In Russian).

12. Stepanova E. Uvol'nenie po prichine utraty doverija: pri kakih obstojatel'stvah ono vozmozhno? (Dismissal on the ground of loss of trust: under what circumstances is it possible?) // Trudovoe pravo. 2014. No.9. P. 71-78. (In Russian). 